MYERS, R. D., \& CICERO, T. J. Are the cerebral ventricles involved in thirst produced by a cholinergic substance? Psychon. Sci., 1968, 10, 93-94.

ROUTTENBERG, A. Drinking induced by carbachol: Thirst circuit or ventricular modification? Science, 1967, 157, 838-839.

\section{NOTE}

1. This research was supported by the Graduate School of the University of Wisconsin-Milwaukee from funds supplied by the Wisconsin Alumni Research Foundation.

\title{
Reply to Bignami
}

BARTON MEYERS, DEPARTMENT OF PSYCHOLOGY, BROOKLYN COLLEGE OF THE CITY OF NEW YORK, Brooklyn, N. Y. 11210

There appears to be no dispute between Bignami and me concerning what I believe to be the major points about muscarinic anticholinergic agents and passive avoidance in the rat. A particular demonstration of the absence of an effect on passive avoidance by such an agent (Meyers \& Koenig, 1967) occurring within a context of studies using different behavioral situations and reporting a disruptive effect for these agents (Bignami, 1967; Bovet, Robustelli, \& Bignami, 1965; Meyers, 1965; etc.) strongly suggests that anticholinergic drugs produce no general inability to avoid passively. Rather, it indicates that only in certain situations do anticholinergic drugs impair passive avoidance. The conditions under which a deficit will or will not be observed remains to be elaborated and, of course, the efforts to do this, which Bignami remarks are now underway in his laboratory, are to be welcomed.

It is obvious, as Bignami indicates, that the presence of an external signal for the shock contingency does not guarantee the lack of an effect by anticholinergic agents on passive avoidance behavior. Thus, the discrepant findings observed in various studies which used externally-cued passive avoidance tasks must have resulted from one or more of the many procedural differences which existed among these studies (Bignami, 1967; Bovet et al, 1965; Meyers \& Koenig, 1967).

Finally, Bignami and $I$ are in complete agreement that no single mechanism is currently available to explain the literature for anticholingeric drugs and that recourse to analogy with lesion effects might be fruitful.

\section{REFERENCES}

BIGNAMI, G. Anticholinergic agents as tools in the investigation of behavioral phenomena. In $\mathrm{H}$. Brill, J. O. Cole, P. Deniker, H. Hippius, \& P. B. Bradley (Eds.), Neuro-psycho-pharmacology, Vol. 5. Amsterdam: Excerpta Medica Foundation, 1967. Pp. 819-830.

BIGNAMI, G. Comment on Meyers and Koenig. Psychon. Sci., 1968, 11, 120.

BOVET, D., ROBUSTELLI, F., \& BIGNAMI, G. Etude du conditionnement inhibiteur chez le rat. Action de l'amphetamine, de la chlorpromazine et des agents cholinergiques. C. $R$. Acad. Sci., (Paris), 1965, 260, 4641-4645.

MEYERS, B. Some effects of scopolamine on a passive avoidance response in rats. Psychopharmacologia, (Berl.), 1965, 8, 111-119.

MEYERS, B., \& KOENIG, A. K. Effects of scopolamine on a "gono go" avoidance task in rats. Psychon. Sci, 1967, 9, 143-144. 